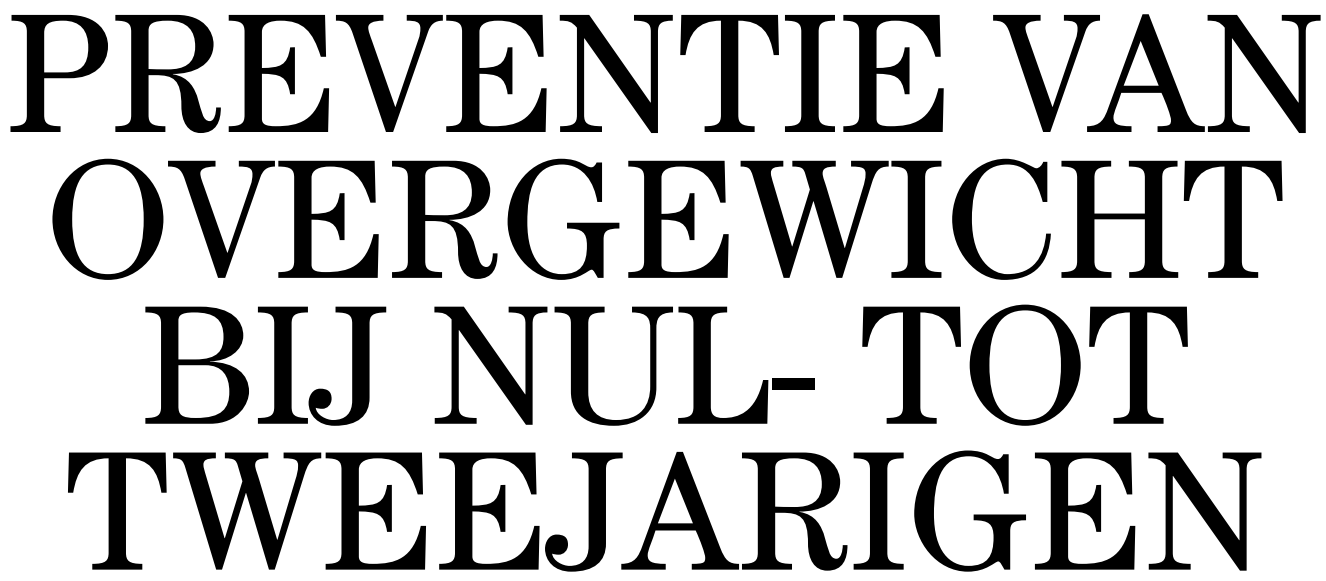

door

EVELIENE DERA DE BIE

docent-onderzoeker Verpleegkunde / Lectoraat wijkgerichte zorg, Team Preventiecentrum - Gezondheid en Welbevinden, Zuyd Hogeschool

\section{De aanpak van}

overgewicht bij kinderen

is een kerntaak

van jeugdartsen

en jeugdverpleeg-

kundigen. Soms

vervullen zij deze rol

niet optimaal. Een

trainingsprogramma

kan helpen hun

bewustzijn te vergroten,

kennis te verbeteren

én het thema

gemakkelijker aan te

snijden bij de ouders.
$\mathrm{N}$

\section{EDERLAND HEEFT EEN GROTE}

groep kinderen en volwassenen

met overgewicht. ${ }^{1}$ Over de levens-

lange negatieve invloed van overgewicht op de gezondheid is al veel bekend. ${ }^{2}$

Actueel zijn de berichten over de relatie tussen overgewicht en het risico op het krijgen van corona. ${ }^{3}$

In de eerste jaren van een kind wordt de basis gelegd voor een gezond leefstijlgedrag voor het verdere leven. ${ }^{4}$ Het is belangrijk om vroegtijdig in te zetten op preventie en zo een gezonde leefstijl bij kinderen te bestendigen. In deze vroege levensperiode van het kind dienen de interventies zich te richten op de ouders. De aanpak van overgewicht bij kinderen is in Nederland een kerntaak van de jeugdgezondheidszorg. De JGZ is een unieke setting, waar vroegtijdig (een risico op) overgewicht kan worden gesignaleerd, een interventie kan worden ingezet en zo nodig kan worden verwezen. ${ }^{5}$

In dit artikel worden de ontwikkeling, uitvoering en resultaten beschreven van een trainingsprogramma voor jeugdartsen en jeugdverpleegkundigen. ${ }^{6}$ Jeugdartsen en jeugdverpleegkundigen hebben vanaf de geboorte van het kind meerdere consultmomenten met ouder en kind. Zij bereiken meer dan 95 procent van de kinderen. Als reactie op de stijgende prevalentie van overgewicht bij kinderen in de afgelopen decennia zijn een landelijke richtlijn overgewicht en tools ter ondersteuning van jeugdartsen en jeugdverpleegkundigen ontwikkeld.? De mate waarin het gebruik van richtlijnen en tools succesvol is, wordt bepaald door de wijze van implementatie.
Mogelijke barrières bij de implementatie zijn bijvoorbeeld een gebrek aan kennis, vaardigheden of tijdgebrek. Een gevolg hiervan kan zijn dat richtlijnen of tools niet adequaat worden geïmplementeerd en gebruikt. ${ }^{8}$ In een eerdere studie zijn drie barrières geïdentificeerd. ${ }^{9}$ De eerste is het onderkennen van het belang dat de eerste levensjaren van een kind een essentiële periode vormen in de preventie van overgewicht. In deze vroege fase is het voor jeugdartsen en jeugdverpleegkundigen onvoldoende duidelijk wanneer (toename van) gewicht bij een kind een risico is voor het krijgen van overgewicht. Dit bemoeilijkt het om vroegtijdig te signaleren. De tweede barrière is

\section{'De interventie- groep heeft minder moeite om overgewicht te bespreken met ouders'}

dat het als moeilijk wordt ervaren om overgewicht bespreekbaar te maken. Tot slot blijkt dat er niet altijd methodisch wordt gewerkt, waardoor bijvoorbeeld materialen niet worden gebruikt. Hoe deze drie barrières aan te pakken? Met behulp van het Intervention Mapping-protocol is hiervoor een training ontwikkeld. Daarbij is er aandacht voor het handelend gedrag van de jeugdartsen 


\section{LEEFSTIJL}

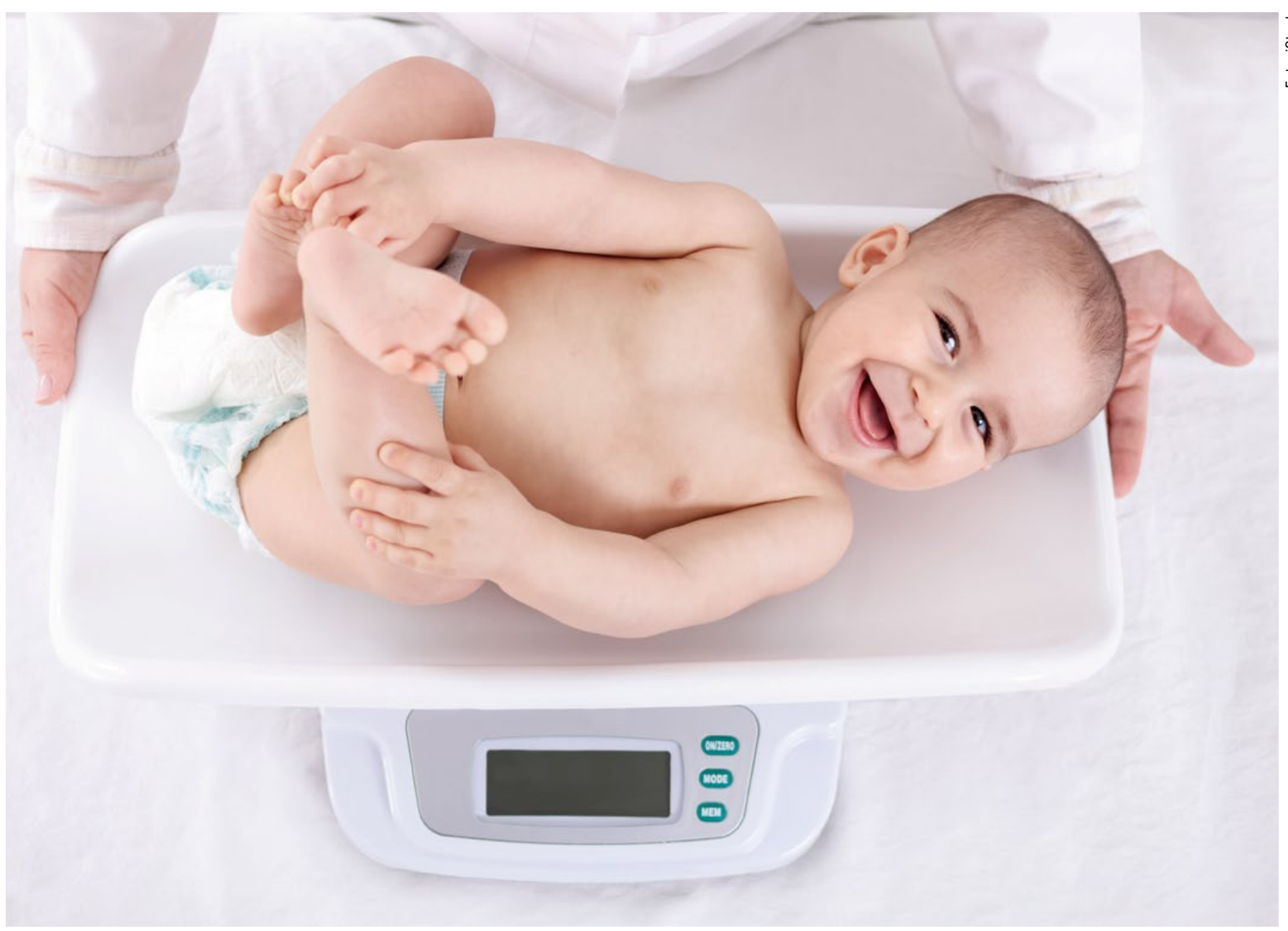

en jeugdverpleegkundigen; dit gedrag is een voorwaarde die de organisatie kan creëren..$^{10}$ Het doel van het trainingsprogramma is een adequater gebruik van de richtlijn en tools in de praktijk.

\section{Training}

Het Intervention Mapping-protocol, dat uit zes stappen bestaat, is als kapstok gebruikt om methodisch een trainingsprogramma te ontwikkelen. ${ }^{10} \mathrm{Het}$ biedt een combinatie van zowel theoretisch bewijs als praktische informatie. Conform het protocol is in de eerste stap onderzocht of er een noodzaak bestaat voor een trainingsprogramma en zijn ook relevante, te veranderen gedragsdeterminanten geïnventariseerd. Aansluitend zijn de doelen opgesteld. Deze zijn opgedeeld in persoonlijke doelen en omgevingsdoelen en de gerelateerde veranderdoelen en determinanten. Vervolgens werden op basis van theoretische methoden gedrags- determinanten geselecteerd. Deze zijn vertaald naar praktische strategieën voor het trainingsprogramma. Na uitvoering van dit programma zijn het proces en effect geëvalueerd. De focus van het trainingsprogramma lag op twee zaken. Eén: het structureel verbeteren van de kennis over vroegtijdig signaleren van een kind van nul tot twee jaar met (risico op) overgewicht. Twee: het aanleren van vaardigheden om het onderwerp bespreekbaar te maken bij de ouders.

De inhoud van het trainingsprogramma bestond uit: 1) een kick-offbijeenkomst; 2) een expertmeeting voor het verwerven van kennis en onderlinge uitwisseling over het thema; 3 ) een aantal vaardigheidstrainingen over motiverende gespreksvoering, specifiek op maat gemaakt voor het thema overgewicht bij kinderen; 4) observaties en coaching on the job bij de individuele jeugdverpleegkundige of jeugdarts; 5) het structureel delen van informatie via nieuwsbrieven of tijdens overlegmomenten; 6) inter- visiebijeenkomsten en; 7) vaste aandachtfunctionaris voor consultering.

\section{'Ongezonde leefstijl en afwijkende groei vroeg
signaleren"}

\section{Deelnemers}

$\mathrm{Er}$ is quasi experimenteel een onderzoek uitgevoerd. Hierbij werd een interventiegroep vergeleken met twee controlegroepen. Voor de procesevaluatie is gebruikgemaakt van een logboek waarin de 
inhoud en organisatie van het trainingsprogramma zijn beschreven. Het effect van de training is gemeten met een vragenlijst die bestaat uit 105 items op een vijfpunts-Likertschaal. De deelnemers hebben de lijst twee keer ingevuld: vóór en een jaar na de afronding van de training. Bij elk item op de vragenlijst is de score van de nameting afgetrokken van de score van de voormeting. Verder is een Paired Sample T-Test uitgevoerd voor elke individuele vraag.

\section{Resultaten}

Binnen de interventiegroep hebben 21 van de 33 deelnemers de vragenlijst ingevuld tijdens zowel de voor- als nameting. Bij de eerste controlegroep deden 26 van de 44 deelnemers dit en bij de tweede controlegroep 14 van de 29.

De belangrijkste bevinding is dat zich bij de interventiegroep een grotere positieve toename voordoet dan binnen de controlegroepen. Het gaat allereerst om meer bewustzijn van het belang van preventie van overgewicht, zeker in het eerste levensjaar van het kind. Verder is binnen de interventiegroep meer kennis ontstaan over de richtlijn en ondersteunende tools. Dit leidt tot een meer methodische werkwijze. Tot slot hebben deelnemers uit de interventiegroep minder moeite om met ouders het (risico op) overgewicht te bespreken. In het algemeen geven de deelnemers uit de interventiegroep aan dat de richtlijn en ondersteunende tools beter zijn geïmplementeerd in de organisatie.

\section{Meerwaarde praktijk}

Uit de resultaten blijkt dat een meer actieve strategie, waaronder een trainingsprogramma op maat, positief bijdraagt aan het gedrag van de jeugdartsen en jeugdverpleegkundigen. Dit gaat gepaard met een betere inbedding en beter gebruik van de richtlijn overgewicht en tools.

De motivatie van de ouders is de belangrijkste factor voor het welslagen van het aanleren van een gezonde leefstijl bij het kind. Voor ouders en kinderen is het moeilijk om gezonde keuzes te maken in onze voedselrijke omgeving. Jeugdartsen en jeugdverpleegkundigen zien bijna alle kinderen vanaf de geboorte. Zij hebben de gelegenheid vroegtijdig een ongezonde leefstijl en afwijkende groei te signaleren en educatie over een gezonde leefstijl aan te bieden aan bijna alle kinderen en hun ouders.

Er is steeds meer aandacht voor het belang van het voorkomen van overgewicht bij kinderen. Positief zijn de ontwikkelingen van een JGZ-preventieagenda, het Nationaal Preventieakkoord en het Landelijk model keten-

\section{'Een trainings- programma draagt bij aan beter gebruik van de richtlijn overgewicht'}

aanpak voor kinderen met overgewicht en obesitas. Jeugdverpleegkundigen, die een rol hebben als centrale zorgverlener, zijn veelal de spil in deze ketenaanpak. Zij dragen er zorg voor dat ondersteuning en zorg op elkaar zijn afgestemd. Samenwerking in de keten is van belang, zodat kind en ouders de ondersteuning krijgen die is afgestemd op hun hulpvraag en behoefte.

\section{REFERENTIES}

1. www.volksgezondheidenzorg.info/onderwerp/ overgewicht

2. World Health Organisation. Obesity and overweight. Fact sheet N311.2015.

3. Lighter J, Phillips M. Hochman S, e.a. Obesity in patients younger than 60 years is a risk factor for COVID-19 hospital admission. Clinical Infectious Diseases. 2020.

4. Singh AS, Mulder C, Twisk JW, e.a. Tracking of childhood overweight into adulthood: a systematic review of the literature. Obes Rev. 2008:9:474-88.

5. www.ncj.nl/themadossiers/ uitvoeringskader/landelijkprofessioneel-kader/

6. Dera-de Bie E, Gerver WJ \& Jansen M. Training program for overweight prevention in the child's first year. Nurs Health Sci. 2013.

\section{Dunnink $G$ \&}

Lijs-Spek WJG. Activiteiten Basistakenpakket Jeugdgezondheidszorg 0-19 jaar per contactmoment. Bilthoven. RIVM. 2008.

8. Dunnink T. Guidelines are not implemented naturally. Dutch Youth Care Magazine. 2013:45(3):72-73.

9. Dera-de Bie E, Gerver WJ \& Jansen M. Inhibiting factors in the prevention of overweight in infants: An explorative study conducted with $\mathrm{CHC}$ practitioners in the Netherlands. $\mathrm{CHCin}$ Practice. 2012;18(3):193-206. 10.Bartholomew LK, Parcel GS, Kok G, e.a. Planning Health Promotion Programs: An intervention Mapping Approach, Edition 2. New York: Mcgraw-Hill Companies. 2006. 